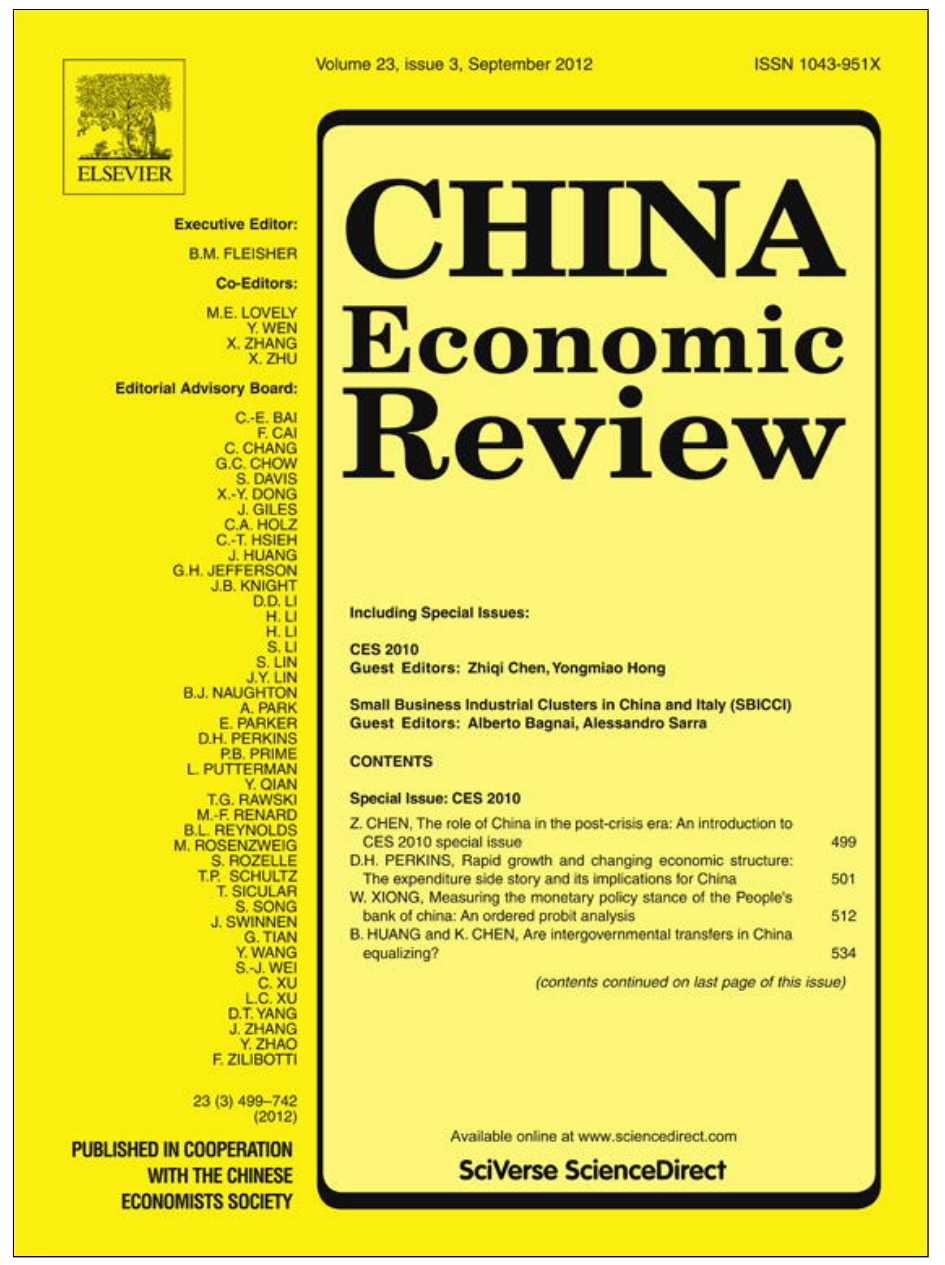

This article appeared in a journal published by Elsevier. The attached copy is furnished to the author for internal non-commercial research and education use, including for instruction at the authors institution and sharing with colleagues.

Other uses, including reproduction and distribution, or selling or licensing copies, or posting to personal, institutional or third party websites are prohibited.

In most cases authors are permitted to post their version of the article (e.g. in Word or Tex form) to their personal website or institutional repository. Authors requiring further information regarding Elsevier's archiving and manuscript policies are encouraged to visit:

http://www.elsevier.com/copyright 


\title{
Industrial development policies and performances in Southern China: Beyond the specialised industrial cluster program
}

\author{
Elisa BARBIERI *, Marco R. DI TOMMASO, Stefano BONNINI \\ University of Ferrara, Ferrara, Italy
}

\section{A R T I C L E I N F O}

\section{Article history:}

Received 29 September 2010

Received in revised form 22 December 2010

Accepted 24 December 2010

Available online 13 January 2011

\section{JEL classification:}

$\mathrm{O} 25$

038

\section{Keywords:}

Industrial development policies

Industrial clusters

Policy evaluation

Innovation

Industrial performance

Guangdong

China

\begin{abstract}
A B S T R A C T
The paper offers an updated picture of the policies implemented by the government of the Guangdong Province (China) to foster the industrial development and the technological upgrading of its territories. Among these policies is the promotion and the institutional acknowledgement of a growing number of industrial clusters, defined as "Specialised Towns", characterized by a high spatial concentration of firms producing one specific item (or a limited range of similar products). In the view of the provincial and local governments these types of industrial development programs are used to increase firm agglomerations, spatial concentration and visibility, which in turn leads to increased specialisation, industrial output, innovation and economic growth. However, little specific empirical evidence has been collected to support this view and the debate, at the national and international level, on the effectiveness of such interventions seems to be still largely ideological. The paper offers a contribution in this sense by offering a detailed description of the policy tools, by suggesting synthetic indexes to quantify policy efforts and industrial performances in Guangdong territories and by providing a first statistical analysis of these indexes.
\end{abstract}

(c) 2011 Elsevier Inc. All rights reserved.

\section{Introduction ${ }^{1}$}

In many ways Guangdong Province is an icon of the unique industrial development that China has been experiencing in the last decades. Located in the Southern part of the country and facing Hong Kong and Macau, Guangdong hosts $7.2 \%$ of the total population of China, if considering both permanent population and people with residence registration coming from other provinces (NBS (National Bureau of Statistics of China), 2009).

It produces the highest GDP among provinces and municipalities in China, about 530.5 billion US\$ in 2008, equal to 12\% of the national total, generated mainly by industry (52\%) and services (43\%) (NBS (National Bureau of Statistics of China), 2009).

It is also among the Chinese provinces attracting the highest amount of foreign direct investments (FDI): $20.7 \%$ of the whole China in 2008 (NBS (National Bureau of Statistics of China), 2009), with a massive presence of firms financed with investments from Hong Kong, Macau and Taiwan.

Moreover, Guangdong accounts for the main import and export quota among the Chinese provinces, representing about 26.7\% of total Chinese foreign trade in 2008 (NBS (National Bureau of Statistics of China), 2009). The average annual growth rate of exports between 2000 and 2008 amounted to 20.38\% (NBS (National Bureau of Statistics of China), 2009).

\footnotetext{
* Corresponding author. Faculty of Economic Studies, University of Ferrara, Via Voltapaletto, 11-44121 Ferrara, Italy.

E-mail address: elisa.barbieri@unife.it (E. Barbieri).

${ }^{1}$ Although the paper is the result of a constant joint work among the authors a possible attribution of the paragraphs is the following: Di Tommaso par. 1 and 2; Barbieri par. 3, 4 and 5; Bonnini Annex.
} 
The rapid development of Guangdong manufacturing sector has been favoured by foreign investments, especially in the Pearl River Delta (PRD) region, ${ }^{2}$ which accounted alone for 8.8\% of China's GDP in 2008 and for 27\% of China's total export (NBS (National Bureau of Statistics of China), 2009). To testify to the concentration of wealth in this region the per-capita GDP of the Pearl River Delta in 2008 was about 62,6000 RMB (about 7130 US\$) - much higher than the 37,589 RMB (about 4280 US\$) of Guangdong Province or 22,698 RMB (about 2585 US\$) of the whole China - with some outstanding figures in the cities of Shenzhen (89,814 RMB, about 13,349 US\$), Guangzhou (81,233 RMB, i.e. 12,074 US\$) and Foshan (72,975 RMB, equal to about 10,846 US\$) (NBS (National Bureau of Statistics of China), 2009).

The opening process of the Chinese economy started in Guangdong and in the Pearl River Delta, in particular through the establishment of special economic zones (SEZ), where the national and the local governments could "test" the functioning of a market economy. In this scenario, the international perception on China and Guangdong is that a shift towards a market-led economy has taken place in the last thirty years, but with a prominent role of the government in the transition process. However, while for some commentators it is thanks to government intervention and industrial development policies that the economy could burst, for others it is despite of such interventions that the growth occurred (Nee \& Opper, 2007; Nee \& Cao, 1999; Parish \& Michelson, 1996). A significant part of such a debate seems to be largely theoretical and ideological. However, some very detailed descriptions at the level of single industrial clusters or single firms in different parts of China show that, when looking at the microlevel, government policies appear to have played a role and, at least in the perception of several actors (firms, entrepreneurs, scholars, and experts), it was an effective role (Arvanitis \& Qiu, 2009; Unger \& Chan, 1999; Krug, 2004). In addition, a few contributions from the field of economic geography try to address through causal inference econometric models, the effectiveness of policies in China (see Demurger, Sachs, Woo, Bao, \& Chang, 2002). In this case, the unit of analysis is the province and the investigation is done on the whole country. Although the general conclusion is that policies worked, the definition of policy is mainly related to the creation of special economic zones and development zones, which, the authors argue, are in substance a form of deregulation. Hence, policy suggestions mainly point at deregulation throughout the country.

From our perspective concentrating on the whole "China case" fails to capture the details of the policy programs. The microlevel studies show that SEZ and development zones are not only a matter of deregulation, but public investments are often involved. Moreover, the variety of policy tools is much wider and goes beyond the establishment of special economic zones (Barbieri, Di Tommaso, \& Rubini, 2009a,b; Arvanitis \& Jastrabsky, 2006; Di Tommaso \& Rubini, 2006). Overall what seems to be overlooked is the meso-level. Specific single province studies that try to measure the magnitude and the relevance of policy efforts and industrial performances at the prefecture- and county-level are missing. The available literature provides scattered evidence that specific policy instruments exist, but it fails to a great extent to quantify their relevance across territories and to suggest systematic approaches to compare counties and localities in their overall policy effort and industrial performance. Fan (1995) highlighted the need to shift from provincial level studies to the county scale to capture the complexities of policy intervention. The author's contribution, however, which referred to 1990's data, did not translate into systematic research lines from other international scholars.

This paper aims at contributing to such a debate in different ways: by offering an updated picture of the major industrial development policy tools used in Guangdong, by suggesting synthetic indexes to quantify and analyze policies and performances in Guangdong Province, by offering an updated analysis of the growth trends of such policies and performances in Guangdong prefectures and by presenting a first investigation of the relation between the two variables. The analysis on Guangdong Province, we suggest, should not be read just as an interesting case study, but given the undoubted centrality of Guangdong in world manufacturing, understanding industries and industrial development policies in Guangdong is a way to learn more on how global contemporary industry generally works today. The paper is structured as follows: Section 2 goes through the main industrial development tools used in Guangdong at the local level; Section 3 proposes two synthetic indexes to measure the level of policy effort in different Guangdong territories and to quantify the industrial performance achievements of such territories; Section 4 presents the results of a statistical analysis of the two indexes for the 21 prefectures of Guangdong from 2001 to 2008 . Conclusions and perspectives for future researches are drawn in the final section.

\section{Policies for local industrial development in Guangdong}

\subsection{The open-door policy: SEZ and development zones}

At the end of the Seventies, the Beijing government decided to use Guangdong as a pilot case in order to test a set of initiatives aimed at a gradual opening of the Chinese economy to the world. The so-called open-door policy designed and implemented by Deng Xiaoping was applied in 1980 in Guangdong, by means of the establishment of three special economic zones (SEZs) in Shenzhen, Zhuhai and Shantou. All SEZs were localised in proximity with strategic sources of foreign capital: close to Hong Kong (Shenzhen), Macau (Zhuhai) and facing Taiwan (Shantou). The SEZs were designed as "laboratories" where government could experiment an accelerated economic development and the controlled import of foreign technologies and capital (Barbieri et al., 2009a,b; Bellandi \& Di Tommaso, 2005; Enright, Scott, \& Chang, 2005; Ge, 1999; Jin, 2007; Inaba, Koolhaas, Leong, \& Chung, 2001). Specifically, the experiments carried out in the Special Economic Zones included the attraction and utilisation of foreign

\footnotetext{
2 The Pearl River Delta (PRD) is part of the Guangdong Province and - according to the official definition - it includes the prefectures of Guangzhou, Shenzhen, Zhuhai, Foshan, Jiangmen, Dongguan and Zhongshan, part of Huizhou (the urban district of Huizhou, Huiyang County, Huidong County and Boluo County) and part of Zhaoqing (the urban district of Zhaoqing, Gaoyao and Sihui) (NBS (National Bureau of Statistics of China), 2009).
} 
investments, the acquisition of foreign technology and managerial skills, the promotion of exports and the testing of marketoriented reforms. In order to reach these aims the Special Economic Zones have become mini autonomous societies gathering many different activities, going from the industrial production to the R\&D promotion, from the education to the social well-being (Ge, 1999). A few contributions highlight the role of the SEZ in shaping a path of regional development in Southern China that still determines much of the trajectories of growth and regional disparities we observe today (Arvanitis, Miège, \& Zhao, 2003; Demurger et al., 2002; Fan, 1995).

In addition to the Special Economic Zones, as a consequence of the open door policy implemented in Guangdong (and all over China), there has been a flourishing of various types of development zones in the province, offering different kinds of incentives and benefiting from different levels of autonomy.

The Economic and Technological Development Zones (ETDZs) are approved by the central government and can adopt favourable fiscal policies for their development areas, such as national and local tax reductions or tax holidays for foreign investment (Zhang, 1999). Unlike the SEZs, planned as independent cities, ETDZs have limited autonomy in policy-making and administration (SiuWai \& Bo-Sin, 2005).

The High Tech Development Zones (HTDZs) are also approved by the central government and are specifically aimed at favouring service firms using new technology to increase the value added of their clients. In order to strengthen the development of these areas, Guangdong Government has introduced specific programs to foster research and development in high technology sectors. ${ }^{3}$

The Free Trade Zones (FTZs) or Export Processing Zones (EPZs) are instead supervised by the Customs Administration, granting to specific areas a higher degree of freedom in the import and export of goods, with exemption from specific taxes if re-exported.

Some areas host more than one type of development zone: Guangzhou, for example, is an open coastal city but it also incorporates an Economic and Technological Development District (GETDD), an Export Processing Zone (GEPZ), a High Tech Development Zone (GHIDZ) and a Free Trade Zone (GFTZ) (GETDD (Guangzhou Economic and Technological Development District), 2003). Table 1 in Section 2.3 summarizes the number of development zones for each prefecture.

\subsection{Policies to support industrial clustering: the "Specialised Town Program"}

What emerges from the Chinese literature, the few international contributions and the official documents of the province government is that Guangdong in the last decade has placed particular attention in shaping the "geography" of its industry, influencing the location of firms within the province territory. ${ }^{4}$

In brief we may say that this active policy has been mainly devoted to reach two targets: 1) rationalise the dramatically fast and often chaotic - development of the Pearl River Delta area; and 2) encourage the development of the other lagging areas. In this scenario Guangdong Government planners have considered the agglomeration of specialised firms in some specific localities as a tool to achieve the above mentioned two targets and more in general to promote industrial development, competitiveness, innovation and technological upgrading. In doing this, the Guangdong Government authorities have explicitly referred to the academic international literature and to government practices diffused in several countries around the world (Barbieri et al., 2009a,b).

Although in several cases the agglomeration of (similar or complementary) firms is a spontaneous process, the Guangdong authorities have decided to accelerate and guide this process through specific policy measures. Through the effective slogan "one city-one product" the Guangdong Government has launched in 2000 a program to promote and encourage the growth and development of the so-called "Specialised Towns": spatial agglomerations of enterprises all focused on the production of one specific item (or of a limited range of similar products, or of part of it, or in the same filiere). These Specialised Towns are different from any general industrial agglomeration, because they all have received official recognition by government authorities; such recognition is based on specific criteria and linked to specific firms and town level (Barbieri, Di Tommaso, \& Huang, 2010).

A thorough analysis of those Specialised Towns targeted by Guangdong Government highlights that there are relevant differences in the way they were born, developed and appear today (Bellandi \& Di Tommaso, 2005; Di Tommaso \& Rubini, 2006).

However, although the history of agglomeration might differ from one town to the other, what makes them similar today is the institutional recognition by the government, which represents both an industrial development policy instrument and a signal to the market.

The experience is unique: each potential Specialised Town is studied by a group of government experts that eventually awards the town with the label "Specialised Town"; then a number of financial and preferential policies are granted in order to (further) encourage agglomeration and specialisation; government recognition and policy advantages are expected to guarantee competitiveness, innovation and market visibility rewards. Thus, the promotion of clusters in Guangdong becomes an explicit industrial policy model: a tool used by the government to address more general industrial development aims.

The phenomenon of Guangdong Specialised Towns is still largely overlooked by the international English speaking academic debate. On the contrary, it is instead an emerging issue within the Chinese academia. There are in fact several authors studying, in particular, the evolution of the "Specialised Towns" in Guangdong Province (Chen \& Cheng, 2005; Li, 2002, 2006; Huang, Yang, \& Meng, 2006; Zhao, 2007; Wang, 2002b; 2004; Tang, Xie, \& Lan, 2005; Lu, 2006a; Zhang \& Ling, 2003; DSTGG (Department of Science and Technology of Guangdong Government), 2006b; Huang \& Hu, 2007, only to cite some). However, most of the relevant

\footnotetext{
3 Source: www.getdd.gov.cn.

4 A review of such a literature can be found in Barbieri et al. (2009a,b); Di Tommaso and Rubini (2006) and Bellandi and Di Tommaso (2005).
} 
Table 1

Number of development zones, Specialised Towns and innovation centres in Guangdong Prefectures, 2001 and 2008

Source: authors' elaboration on data from DSTGG and NBS (National Bureau of Statistics of China), various years.

\begin{tabular}{|c|c|c|c|c|c|c|}
\hline \multirow[b]{2}{*}{ Prefectures } & \multicolumn{3}{|l|}{2001} & \multicolumn{3}{|l|}{2008} \\
\hline & Development zones & Specialised Towns & Innovation centres & Development zones & Specialised Towns & Innovation centres \\
\hline Guangzhou & 5 & 1 & 0 & 5 & 4 & 0 \\
\hline Shenzhen & 5 & 0 & 0 & 5 & 0 & 0 \\
\hline Zhuhai & 2 & 0 & 0 & 2 & 4 & 1 \\
\hline Shantou & 1 & 1 & 0 & 1 & 26 & 5 \\
\hline Foshan & 1 & 8 & 11 & 1 & 34 & 20 \\
\hline Shaoguan & 0 & 0 & 0 & 0 & 9 & 1 \\
\hline Heyuan & 0 & 0 & 0 & 0 & 12 & 0 \\
\hline Meizhou & 0 & 0 & 0 & 0 & 17 & 4 \\
\hline Huizhou & 2 & 0 & 0 & 2 & 9 & 0 \\
\hline Shanwei & 0 & 1 & 0 & 0 & 6 & 0 \\
\hline Dongguan & 1 & 4 & 0 & 1 & 13 & 6 \\
\hline Zhongshan & 1 & 4 & 2 & 1 & 14 & 6 \\
\hline Jiangmen & 0 & 1 & 3 & 0 & 19 & 13 \\
\hline Yangjiang & 0 & 0 & 0 & 0 & 6 & 1 \\
\hline Maoming & 0 & 0 & 0 & 0 & 16 & 2 \\
\hline Zhaoqing & 1 & 1 & 0 & 1 & 17 & 2 \\
\hline Qingyuan & 0 & 0 & 0 & 1 & 9 & 2 \\
\hline Chaozhou & 0 & 0 & 6 & 0 & 14 & 4 \\
\hline Jieyang & 0 & 0 & 0 & 0 & 14 & 2 \\
\hline Yunfu & 0 & 0 & 0 & 0 & 19 & 5 \\
\hline
\end{tabular}

material to understand the experience of Specialised Towns has to be found in Guangdong Government documents describing the details of the ongoing practices.

It was the Department of Science and Technology of Guangdong Government (DSTGG) that firstly introduced the idea of "Specialised Town", which is still at the centre of its current industrial policy promotion strategy (Di Tommaso \& Rubini, 2006; Barbieri et al., 2009a,b). The Department officially acknowledges as "Specialised Towns" those meeting the following criteria:

1. the town has to be a "township" from an administrative point of view, or, less frequently, a "county" or an "urban district" and at least $30 \%$ of its industrial output (or employment) has to be concentrated in one industry (defined in specific sectoral terms to the 3-digit level equivalent of international classification systems), that is called "specialised sector";

2. the annual value of the industrial output has to exceed 2 billion Yuan (equal to about 293 million US\$).

The officially recognized Specialised Towns are then entitled to receive funding from the Department of Science and Technology and from the local government. The money is mainly meant to favour the creation of innovation centres or platforms, whose aim is to help firms in the development of new technologies and to favour the birth and consolidation of relations among actors. Through the innovation centres firms should be able to increase the quality of their products and the town will benefit from an improvement in the reputation of the whole city, possibly developing a common and easily recognizable brand (Arvanitis \& Qiu, 2009; Wang, 2004; DSTGG (Department of Science and Technology of Guangdong Government), 2003; DSTGG (Department of Science and Technology of Guangdong Government), 2006b). By the end of 2008 there were 229 Specialised Towns in Guangdong (see Fig. 1), although this number is constantly increasing. ${ }^{5}$

\subsection{Policies for innovation in Guangdong}

One of the priorities identified by the national and provincial governments of China in terms of industrial development is the necessity to increase the innovative capacity and the technology upgrading of firms and territories, so as to allow the industrial system to move up the value chain and to be able to compete at the international level. In other words, industrial upgrading and innovation are seen as key determinants of the capacity to increase competitiveness and to maintain a good export performance in the long run (DSTGG (Department of Science and Technology of Guangdong Government), 2006a; Clark \& Guy, 1997). On one side Chinese policy makers are looking for ways to increase the value added of their industrial productions favouring R\&D-based innovation and the entry in high tech sectors (Di Tommaso \& Huang, 2010; Peng \& Chen, 2009; Cao \& Chen, 2010); on the other, they are also investing on the capacity of national enterprises to produce higher quality and higher value added goods in more traditional sectors, such as textiles, footwear, metal product, furniture, etc. (Xie, 2006; Simmie, 2004; Maskel \& Malmberg, 1999; Barbieri et al., 2010).

Official documents of the National Development and Reform Commission (2009) and of the Department of Science and Technology of Guangdong Government (DSTGG (Department of Science and Technology of Guangdong Government), 2006a,b;

\footnotetext{
${ }^{5}$ In 2010 according to the official website of the DSTGG (www.gdstc.gov.cn) there were 277 Specialised Towns in Guangdong Province.
} 


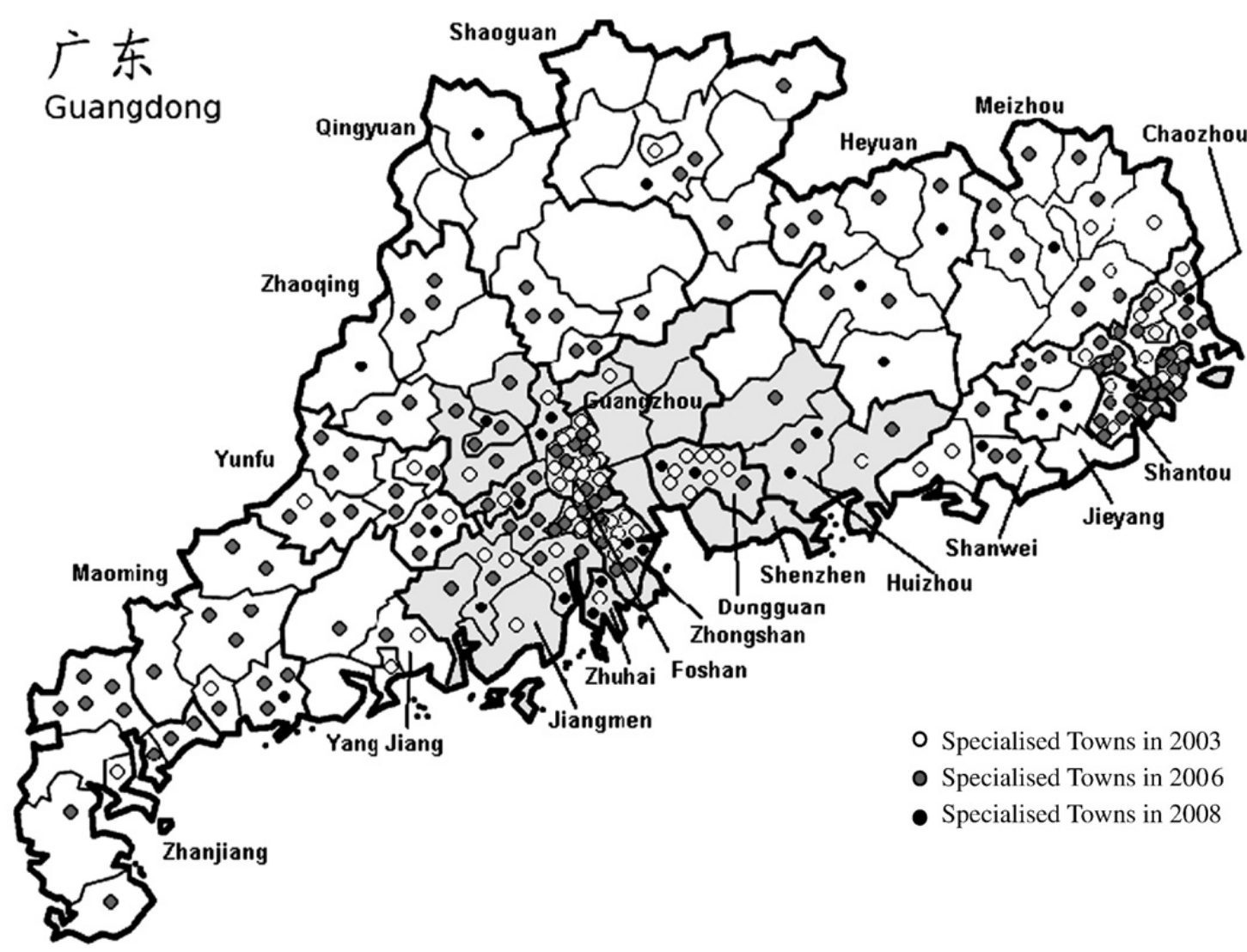

Fig. 1. Specialised Towns in Guangdong Prefectures, 2008. Source: authors' elaboration on Barbieri et al. (2009b).

DSTGG (Department of Science and Technology of Guangdong Government), 2008a) ${ }^{6}$ explain that innovation is considered as the main means to favour the technological upgrading of Guangdong industries and they underline the steps that are being taken in order to promote innovation, with particular reference to Specialised Towns.

There are two main tools supporting innovation that emerge from these documents (Barbieri et al., 2010):

1) the formal acknowledgement of Specialised Towns itself (see Section 2.2), which is encouraged with the aim to increase technological upgrading and innovation by means of increased specialisation;

2) the establishment over time, in each officially recognized Specialised Town, of a "Technology Innovation Platform", providing services aimed at supporting the innovative capacity of the firms operating in the specialised sector of the town.

The innovation platform provides a wide range of different services and activities. Among others: actions of innovation promotion specifically addressing the sector of specialisation, R\&D in industrial engineering, productivity promotion, production of studies and analyses, business incubation, professional consultancy, qualified information gathering and diffusion, development of commercial websites for the promotion of the specialised sector and so on (Xie, 2003; Qiu \& Xu, 2007).

According to surveys carried out by the Department of Science and Technology, up to 2006, innovation platforms were established in 108 Specialised Towns (DSTGG (Department of Science and Technology of Guangdong Government), 2006b). These platforms have common targets but they can differ from town to town according to the form of government intervention. In particular, it is possible to identify three main categories of innovation platform (DSTGG (Department of Science and Technology of Guangdong Government), 2008c; Barbieri et al., 2010):

1) Information networks. The information networks are used to disseminate technology, exchange and diffuse commercial information and carry out internet-based cooperation among actors. In fact, these networks mainly operate by means of websites, allowing the access to online information or to information centres.

2) Innovation centres. The innovation centres are institutions directly created or supported using funding provided by the local and the provincial government.

3) RED centres within leading firms. The third type of innovation platform refers to already existing technology Research \& Development centres in some leading firms of the Specialised Town. According to the Department of Science and Technology,

\footnotetext{
${ }^{6}$ See also for further reference Arvanitis and Jastrabsky (2006), which contains an analysis of the "Report on the Development of Scientific and Technological Research in Guangdong" (Guangdong Office of Science and Technology).
} 
firms have been able to establish these centres thanks to the favourable and innovation-friendly local environment created by the policies implemented by the provincial government. These firm-based centres favour the spillover of knowledge and they are therefore considered to be very important for the innovation capacity of the whole town (Zhu, 2005). In this study we have selected only concrete innovation centres and productivity promotion or service centres, leaving aside for instance websites and the like (first form of innovation platforms). Table 1 summarizes the main figures on development zones, Specialised Towns and innovation centres in Guangdong, in 2001 and 2008.

\section{Measuring policy efforts and industrial performances}

In this section we combine the information collected with the analysis of the single industrial development programs into a synthetic Index of Policy Intensity, in order to measure the degree of policy effort through the years and across the Guangdong prefectures (Section 3.1). Similarly we calculate a synthetic index of the industrial performance for the same territories and years (Section 3.3). To calculate the composite indexes, in addition to the already mentioned official documents of the DSTGG, we collected data through the official statistics at the national, provincial and prefecture level (NBS, various years).

\subsection{Index of Policy Intensity (IPI)}

The Index of Policy Intensity (IPI) is composed of five variables, three of which represent the policy programs analyzed in Section 2 and the remaining two provide a more general indication on government investments in the economy. In order to allow comparisons among the variables and ensure that their values are strictly included in the interval ( 0.1$)$, each one of them has been normalized according to the formula:

$$
\lambda=\frac{X-\min (X)+\frac{1}{21}}{\max (X)-\min (X)+\frac{2}{21}}
$$

The Index of Policy Intensity is then calculated combining the five variables according to the Fisher's combining function:

$$
I P I=-\sum_{I=1}^{k} w_{i} \ln \left(1-\lambda_{i}\right)
$$

where $\lambda_{i}$ indicates the normalized value of the $i$-th variable $X_{i}(i=1,2, \ldots, k)$ and $w_{i}$ represents the weight (degree of importance) of $X_{i}$. In our case $k$ is equal to 5 . The advantage of the Fisher's formula is to result in a simple index that synthesizes different information on the policies adopted in each prefecture. ${ }^{7}$ The formula tends to rank relatively higher prefectures that have a good positioning in all the dimensions taken into account rather than prefectures that excel in only one dimension. The five variables that compose the index are:

1. Specialised towns: the variable indicates for each prefecture and for each year the number of towns officially recognized by the Department of Science and Technology of Guangdong Province. This value is weighted for the number of years passed since each town obtained the official recognition. The hypothesis is that towns that have been recognized earlier behave differently from the newly recognized and might be related in systematic different ways with the performance we observe in the same territories.

2. Development zones: the variable summarizes for each prefecture the number of development zones weighted for the number of years since each one of them was established by the national, provincial or local government.

3. Innovation centres: it identifies innovation platforms, productivity promotion centres and the like, built by the provincial or the local government. Also in this case we have taken into account the number of years since the establishment of each centre.

4. Expenditure/revenues ratio: it is the ratio between the prefecture's government expenditures and revenues. ${ }^{8}$

5. R\&D expenditures: it refers to the expenditures for Research and Development of the public research institutions. They include both the expenditures for basic and applied research, and the management and administration expenditures related to the research activity.

\footnotetext{
${ }^{7}$ In order for this tool to be effective it is necessary to choose a few informative variables and avoid duplications. Therefore before computing the formula we calculated correlations among all the variables that according to us could act as proxies of policy intervention and have excluded one for each pair that displayed correlations extremely close to one.

${ }^{8}$ Government expenditures mainly include the following items: expenditure for capital construction, innovation funds for enterprises, geological prospecting expenses, expenditures for science and technology promotion, expenditure for supporting rural production, operating expenses of the authorities of farming, forestry, water conservancy and meteorology and others, operating expenses of the authorities of industry, transport and commerce, operating expenses of the authorities of culture, education, science and public health, pension for the disabled or for the families of the bereaved and relief funds for social welfare, expenditures for national defence, administrative expenses and expenditure for price subsidies, etc. (NBS (National Bureau of Statistics of China), 2009). Government revenues include (1) Various tax revenues, including value added tax, business tax, consumption tax, land value added tax, city maintenance and construction tax, resources tax, tax on use of urban land, stamp tax, individual income tax, corporate income tax, tariff, tax on agriculture and animal husbandry and tax on occupancy of cultivated land, etc. (2) Special program receipts, including receipts of pollutant discharge fee, urban water resource charge, education surtax, etc. (3) Other receipts, including receipts of the repayment of capital construction loan, income of capital construction projects, donations, etc. (4) Planned subsidies to the loss of the state owned enterprises (negative item) (NBS (National Bureau of Statistics of China), 2009).
} 
Table 2

Index of Policy Intensity in Guangdong ${ }^{\mathrm{a}}$, rankings 2001 and 2008.

Source: authors' elaboration in data from DSTGG and NBS (National Bureau of Statistics of China), various years.

\begin{tabular}{|c|c|c|c|c|c|}
\hline Prefecture & Ranking 2001 & Region & Prefecture & Ranking 2008 & Region \\
\hline Guangzhou & 0.9925 & PRD & Guangzhou & 0.9927 & PRD \\
\hline Foshan & 0.3453 & PRD & Foshan & 0.4881 & PRD \\
\hline Heyuan & 0.1406 & & Heyuan & 0.1173 & \\
\hline Shenzhen & 0.0462 & PRD & Shenzhen & 0.0527 & PRD \\
\hline Zhongshan & 0.0420 & PRD & Meizhou & 0.0503 & \\
\hline Chaozhou & 0.0355 & & Shantou & 0.0394 & \\
\hline Zhanjiang & 0.0232 & & Jiangmen & 0.0389 & PRD \\
\hline Dongguan & 0.0214 & PRD & Yunfu & 0.0358 & \\
\hline Meizhou & 0.0206 & & Jieyang & 0.0349 & \\
\hline Qingyuan & 0.0190 & & Zhanjiang & 0.0348 & \\
\hline Shantou & 0.0168 & & Chaozhou & 0.0321 & \\
\hline Huizhou & 0.0166 & & Yangjiang & 0.0291 & \\
\hline Yunfu & 0.0151 & & Zhongshan & 0.0232 & PRD \\
\hline Shanwei & 0.0138 & & Maoming & 0.0230 & \\
\hline Jiangmen & 0.0136 & PRD & Shanwei & 0.0208 & \\
\hline Zhuhai & 0.0123 & PRD & Zhaoqing & 0.0183 & \\
\hline Yangjiang & 0.0113 & & Dongguan & 0.0138 & PRD \\
\hline Zhaoqing & 0.0110 & & Qingyuan & 0.0132 & \\
\hline Maoming & 0.0090 & & Huizhou & 0.0131 & \\
\hline Shaoguan & 0.0085 & & Shaoguan & 0.0084 & \\
\hline Jieyang & 0.0075 & & Zhuhai & 0.0073 & PRD \\
\hline
\end{tabular}

${ }^{\mathrm{a} C o m p o s i t e}$ index of the following variables: number of Specialised Towns, number of development zones, number of innovation centres, public expenditures/ revenues, R\&D public expenditures.

The index itself has been normalized so as to have values between 0 and 1 . An index close to 1 signals a high policy effort in a prefecture.

\subsection{Policy intensity among prefectures}

Table 2 shows a ranking of the prefectures according to the values of the Index of Policy Intensity for 2001 and 2008.

In 2001 the prefectures that display a higher policy effort are the central ones of the Pearl River Delta together with the eastern ones of Heyuan and Chaozhou. In particular Guangzhou, Foshan, Shenzhen and Zhongshan in PRD are the ones with the highest indexes in 2001. In other words, in 2001 the policy efforts seem to be still largely linked to the early interventions of the SEZ in the Pearl River Delta and in the eastern part of the province.

In 2008 some clear changes in the distribution of the policy effort are visible in particular in favour of the areas surrounding the PRD. The policy effort seems to literally shift from the PRD to areas outside. Apart from Jiangmen (that is part of the PRD) all the prefectures that display an improvement in their position from 2001 to 2008 are outside the Pearl River Delta. In particular, they are in the eastern part of the province (Meizhou, Shantou, Jieyang) and in the western area (Yunfu, Yangjiang, Maoming). Zhaoqing is the only central inner prefecture displaying an (moderate) increase in the IPI.

These data appear to confirm the trends in policy intervention stated in the long-term programs, officially diffused by the national and provincial government. ${ }^{9}$ The patterns of institutionalization of new Specialised Towns and innovation centres in specific areas of the province are meant to go in the direction of relocating part of the industries of the Pearl River Delta in outer prefectures, solve congestion problems in the PRD, shift the production to higher value added sectors in the PRD, while moving more traditional specialisations outside the Delta (Barbieri et al., 2009a,b). Altogether in 2008 the greater policy efforts in terms of investment attraction, increased agglomeration and investment in R\&D are, de facto, observed outside the Pearl River Delta.

\subsection{Index of Industrial Performance}

The Index of Industrial Performance (PERF) has been calculated following the same procedure described in Section 3.1. Once the variables have been normalized and the correlations calculated, we have selected four indicators for industrial performance, which have been combined again with the Fisher's function.

$$
P E R F=-\sum_{I=1}^{k} w_{i} \ln \left(1-\lambda_{i}\right)
$$

The variables in this case have been selected according to the aims of the major industrial policy programs promoted by the provincial government. As a whole the analyzed programs aim at promoting industrial growth, technology upgrading and

\footnotetext{
${ }^{9}$ See for instance the Coordinated Plan for the Development of Pearl River Delta 2006-2020, or the Five-Year Development Programs of the Guangdong Province (Greater Pearl River Delta Business Council, 2006a,b).
} 
Table 3

Index of Industrial Performance ${ }^{\mathrm{a}}$, rankings 2001-2008.

Source: authors' elaboration in data from DSTGG and NBS (National Bureau of Statistics of China), various years.

\begin{tabular}{|c|c|c|c|c|c|}
\hline Prefetture & 2001 & Region & Prefetture & 2008 & Region \\
\hline Shenzhen & 0.9979 & PRD & Shenzhen & 0.9980 & PRD \\
\hline Guangzhou & 0.0600 & PRD & Foshan & 0.0287 & PRD \\
\hline Jieyang & 0.0412 & & Guangzhou & 0.0265 & \\
\hline Dongguan & 0.0354 & PRD & Dongguan & 0.0216 & PRD \\
\hline Foshan & 0.0336 & PRD & Zhongshan & 0.0140 & PRD \\
\hline Zhongshan & 0.0233 & PRD & Jieyang & 0.0139 & PRD \\
\hline Shantou & 0.0195 & & Shantou & 0.0091 & \\
\hline Jiangmen & 0.0117 & PRD & Jiangmen & 0.0064 & PRD \\
\hline Chaozhou & 0.0104 & & Zhuhai & 0.0058 & PRD \\
\hline Zhuhai & 0.0104 & PRD & Chaozhou & 0.0053 & \\
\hline Maoming & 0.0071 & & Maoming & 0.0041 & \\
\hline Zhanjiang & 0.0062 & & Zhanjiang & 0.0038 & \\
\hline Zhaoqing & 0.0059 & & Shanwei & 0.0036 & \\
\hline Meizhou & 0.0058 & & Qingyuan & 0.0034 & \\
\hline Shanwei & 0.0049 & & Zhaoqing & 0.0031 & \\
\hline Yangjiang & 0.0039 & & Yangjiang & 0.0028 & \\
\hline Qingyuan & 0.0028 & & Shaoguan & 0.0026 & \\
\hline Yunfu & 0.0025 & & Heyuan & 0.0024 & \\
\hline Heyuan & 0.0021 & & Yunfu & 0.0020 & \\
\hline
\end{tabular}

${ }^{\mathrm{a}}$ Composite index of the following variables: firm density, industrial value added, output of new products, exports.

competitiveness of local industries. Some of the analyzed programs such as the Specialised Town program and the development zones try to do this by shaping the concentration of firms in specific clusters in order to favour specialisation. Others, such as innovation centres and investments in $\mathrm{R} \& \mathrm{D}$, aim also at promoting innovation directly, through financing and services. Based on these considerations the selected variables for each prefecture ${ }^{10}$ are:

1. Density: it measures the density of industrial firms per square kilometer. This aspect is taken into account since the analyzed program, particularly the Specialised Towns program (but also the development zones) aim specifically at creating agglomeration, thus increasing the density of firms.

2. Value added: it measures the industrial value added produced by industrial firms in the different prefectures. It is taken as a proxy to monitor the industrial growth. Alternatively the industrial output can be used, given that the two have a correlation very close to one.

3. Output of new products: it represents the value of new products realized by industrial ADS firms. New products refer to both items realized with new technology and to products that display a better performance thanks to changes in their structure, materials and production processes.

4. Export: it measures the total value of export produced by Guangdong industrial firms and directed outside the Chinese borders. Given that Guangdong industry is mainly export-oriented, the trends in exports can give information on the capacity of industries to compete in the international markets.

Again, the index itself has been normalized and values close to 0 indicate a low industrial performance, while values close to 1 indicate a high performance with respect to the other prefectures.

\subsection{Industrial performance among prefectures}

Table 3 shows the rankings of Guangdong's prefectures according to the values of the Performance Index in 2001 and 2008.

In 2001 the highest performances are registered in the Pearl River Delta in particular in Shenzhen, Guangzhou, Dongguan, Foshan, Zhongshan and in the eastern prefecture of Jieyang. In general the PRD prefectures can be found in the first half of the ranking, above the median value (0.0104).

In 2008 only a few changes can be observed. The PRD prefectures remain all above the median value (0.0053) and three out of the six prefectures that increase the Performance Index are in the PRD (Foshan, Zhongshan, Zhuhai). The remaining three are the eastern prefectures of Shanwei and Heyuan and the central inner area of Qingyuan.

Altogether the observed trend of industrial performance throughout the period 2001-2008 does not seem to point at a clear change in the distribution of high performance in the province. Contrary to what we observe for the Index of Policy Intensity, the core of the industrial production and concentration seem to remain basically in the PRD and partly in the eastern coastal regions.

\footnotetext{
10 Official statistics at the prefecture level provide most of the economic indicators only for firms Above Designated Size (ADS) whose turnover exceeds 5 million RMB. However, we know for each prefecture the contribution that these give to the Prefecture with respect to the considered dimensions. We use this information to calculate the value of each variable.
} 


\section{Policy and performances: perspectives from the two indexes}

A look at the correlation between the two indexes can reveal further regularities in the behaviors of Guangdong territories with respect to policy intervention and industrial performance. This last exercise should be read as a first step of an ongoing research on the effectiveness of industrial development policies in China. It is important to highlight that there is no counterfactual estimation in this analysis and therefore we cannot verify the existence of a causal relationship between the policy and the Performance Indexes. At this stage we investigate the statistical correlation existing between the two indexes and observe such a correlation for each prefecture and for a homogeneous group of prefectures. We do not expect such a correlation to be exactly the same throughout the whole province, as there are factors that make some prefectures systematically different from the others (the existence of a SEZ, the proximity to the coast, the proximity to the Pearl River Delta and so forth). Given the nature of the data and the problem that we are investigating, to perform the test on correlation we applied a nonparametric multistrata permutation test (see Annex), according to the NPC Test methodology (Pesarin \& Salmaso, 2010).

We tested the hypothesis that there is a positive correlation between the two indexes for the 21 prefectures of Guangdong for the seven years considered (2001-2008). We then tested the same hypothesis for sub-groups of prefectures, that have been identified according to:

a) the overall trend in the policy index: some prefectures display policy efforts that are always increasing, others show a decreasing policy index for all the years and the remaining do not exhibit a clear strategy in this sense;

b) the geographical location, in terms of proximity to a Special Economic Zone, to the Pearl River Delta and to the coast: given the historical relevance of SEZ in the development of Guangdong, being a SEZ or bordering a SEZ defines a background environment where the relations of policies with performances (and subsequently the effectiveness of policies) can be systematically different from other areas. The same can be said for prefectures that are part of the Pearl River Delta (close to the river, the capital city Guangzhou and Hong Kong) and in general for coastal prefectures that can be more easily accessed with respect to the mountainous, more marginal areas, in the north of the province.

\subsection{Results from the statistical analysis}

Tables 4 and 5 show the results of the statistical analysis. Table 4 summarizes the p-value of the partial correlation tests for each prefecture and the classification in sub-groups according to the trend in the policy index and the geographical location. Table 5 displays the p-values of the test for each sub-group. The prefectures of Guangzhou and Shenzhen are not considered in this analysis since they represent for all the years the best performers (respectively in the policy index and Performance Index) and therefore they register constant values of the indexes close to 1 , which makes a correlation in this case little informative and conceptually misleading.

The partial correlations are significant for the prefectures of Zhuhai, Huizhou, Dongguan and Zhongshan, while for remaining prefectures there is no evidence of a positive correlation between the two indexes.

Table 4

NPC partial correlation between Index of Policy Intensity and Index of Industrial Performance and sub-group classification. Source: authors' elaboration in data from DSTGG and NBS (National Bureau of Statistics of China), various years.

\begin{tabular}{|c|c|c|c|c|c|}
\hline Prefecture & p-value & Policy index trend 2001-2008 & Special Economic Zone (or adjacent) & Pearl River Delta & Coast \\
\hline Zhuhai & $0.015^{* *}$ & mixed & YES & YES & YES \\
\hline Shantou & 0.977 & increasing & YES & NO & YES \\
\hline Foshan & 0.673 & increasing & NO & YES & NO \\
\hline Shaoguan & 0.547 & mixed & NO & NO & NO \\
\hline Heyuan & 0.997 & decreasing & NO & NO & NO \\
\hline Meizhou & 0.982 & increasing & NO & NO & NO \\
\hline Huizhou & $0.002^{* * *}$ & mixed & YES & NO & YES \\
\hline Shanwei & 0.872 & increasing & NO & NO & YES \\
\hline Dongguan & $0.001^{* * *}$ & decreasing & YES & YES & YES \\
\hline Zhongshan & $0.096^{*}$ & decreasing & YES & YES & YES \\
\hline Jiangmen & 0.998 & increasing & YES & YES & YES \\
\hline Yangjiang & 0.997 & increasing & YES & NO & YES \\
\hline Zhanjiang & 0.965 & increasing & NO & NO & YES \\
\hline Maoming & 0.900 & increasing & NO & NO & YES \\
\hline Zhaoqing & 0.957 & increasing & NO & NO & NO \\
\hline Qingyuan & 0.973 & mixed & NO & NO & NO \\
\hline Chaozhou & 0.635 & mixed & YES & NO & YES \\
\hline Jieyang & 0.984 & increasing & YES & NO & YES \\
\hline Yunfu & 0.997 & increasing & NO & NO & NO \\
\hline
\end{tabular}

** Significant at level 0.05 .

*** Significant at level 0.01 .

* Significant at level 0.1. 
Table 5

NPC partial correlation between Index of Policy Intensity and Index of Industrial Performance by sub-group.

Source: authors' elaboration in data from DSTGG and NBS (National Bureau of Statistics of China), various years.

\begin{tabular}{|c|c|c|c|c|c|c|c|}
\hline Policy index trend 2001-2008 & p-value & Pearl River Delta & p-value & Special Economic Zone & p-value & Coast & p-value \\
\hline Increasing & 0.9301 & YES & $0.005^{* *}$ & YES & $0.008^{* *}$ & YES & $0.009^{* *}$ \\
\hline Decreasing & $0.002^{* * *}$ & NO & $0.017^{*}$ & NO & 0.964 & NO & 0.961 \\
\hline Mixed & $0.014^{*}$ & & & & & & \\
\hline Total & $0.002^{* * *}$ & Total & $0.005^{* *}$ & Total & $0.005^{* *}$ & Total & $0.014^{*}$ \\
\hline
\end{tabular}

** Significant at level 0.05

*** Significant at level 0.01 .

* Significant at level 0.1 .

The information contained in the p-values of these partial tests is used to compute the sub-group correlations, which take into account also the dimensions related to the geographical location and the trends in policy efforts.

This latter set of tests reveals that:

a) the correlation between policy and performance is statistically significant for prefectures that have had a constantly decreasing policy effort or a mixed strategy (not constantly decreasing or increasing). For the former, along with a decreasing policy effort, the performances have been decreasing; the latter have similar performance and policy trends (meaning that when one increases the other increases too and vice versa). On the other hand, according to the NPC test, prefectures that have constantly increased their policy effort do not necessarily show an increasing performance; there is no evidence for a positive correlation in this case. This in general does not mean that policies have no effects: it could be, for instance, that policies contributed to slow down a trend in the performance that in the previous decades was decreasing at an even faster pace than the one we observe. Further analysis is required on this through the collection of historical time series data;

b) the correlation between the two indexes is statistically significant for prefectures that host a SEZ or that border a SEZ;

c) coastal prefectures display a significant positive correlation between the two indexes, while the hypothesis of positive correlation is not verified for the inner mountainous region;

d) being outside or inside the PRD area does not seem to make a difference, both tests are significant.

The further combination of the p-values of the subgroup tests produces an overall test of significance (the "total" value, displayed in the last row of Table 5) that allows accepting the hypothesis of a general positive correlation between the two indexes.

In other words, there are two main findings suggested by the statistical analysis with the NPC test.

First of all we can generally conclude that there is a positive correlation between the Index of Policy Intensity and the Performance Index, once the confounding factors are taken into account.

Secondly, these confounding factors turn out to be determinant dimensions of the relation between policies and performances. They therefore need to be taken into account in further analyses on the effects of local industrial development policies. We cannot verify at this stage a causal relationship between the two indexes, however we can suggest that the geographical location on the coast and the early policy interventions of the SEZ still matter and constitute evident discriminating factors when investigating such a relationship. Moreover, these factors seem to be even more relevant in describing the relationship than a constantly increasing policy effort that, on the contrary, takes place to a great extent outside the PRD and outside the SEZ.

\section{Some final remarks}

This paper is written to offer a contribution to the debate on China's economic growth and to the more general debate on contemporary industry and industrial policy. The first consideration is on the choice of our object of analysis: Guangdong is not just an interesting case study, it is where a relevant part of global manufacturing is realized and it is the place where the transition of China towards a market oriented economy started. Studying Guangdong in particular is a way for us to understand contemporary industry in general and contemporary industrial policies in the international market.

The second consideration is methodological. We offer a contribution to the debate on the role of governments in China by choosing a precise methodology: we use the details of a specific provincial case study to address issues of a wider relevance. In particular, we go into the details of policy intervention in two ways (1) zooming on the territories, that are the different administrative regions of the Guangdong Province, and (2) zooming on the tools, that are the specific industrial development programs promoted by the provincial and the local governments. We combined the information collected in this way into synthetic indexes able to provide a picture of the distribution of policy efforts and industrial performance across territories and over time. The detailed description of the case study and the analysis on the indexes show that:

1) policy intervention exists and it is extensively used across Guangdong Province. It has specific and strategic aims: shape the geography of production, promote the agglomeration of firms in specific areas, increase industrial specialisation, as it is confirmed by the variety of policy tools employed; 
2) industrial policy makers in Guangdong consider "space" as a strategic component and they place particular attention on the geography of production and on the advantages of agglomeration, as it is confirmed by the dynamism and acceleration of programs such as the one supporting "Specialised Towns";

3 ) the distribution of policy efforts within the province seems to follow very closely the long term development goals stated in the official documents of the central and local governments. According to the synthetic policy index proposed, there is a shift of policy effort from the PRD region to the eastern and western prefectures of the province, which is coherent with the government stated attempt to even out territorial unbalances;

4) as regards the industrial performance, according to the composite index proposed, the highest performances are still very much concentrated in the PRD area;

5) Once the confounding factors related to the geographical location and to the strategies of policy efforts are taken into account, the statistical correlation between the two indexes is positive and significant.

The data that we observe support the view that the geographical location, together with the very first policy interventions of the '80s, have created a path dependency in the growth process of the province that has lead to a concentration of industrial performances in the PRD and around the SEZ. Such a concentration is still observable and does not seem to change despite the diffusion of policy efforts outside these areas. In this scenario, we cannot conclude that more recent policies are ineffective. Recent policy instruments might still be effective in that they could be contributing to decelerate such a concentration and to gradually switch to a scenario where the increase in the industrial performances involves more marginal areas. The amount of data required to verify in a rigorous way this hypothesis is large and it implies data collection at even lower administrative levels (county and township) and for longer periods of time. Furthermore, the assumptions normally made in the consolidated models of causal inference and counterfactual estimation are often very stringent and leave aside much of the complexity involved in industrial development programs, however we believe that future researches in the national and international debate on the effectiveness of policies in China should take the chance and move forward in this direction.

\section{Annex}

\section{Details on the NPC methodology and test}

The NPC Test method (Pesarin \& Salmaso, 2010) is based on the idea that a complex (global) test of hypothesis can be decomposed in many sub-problems (partial tests) and that the result for the global test can be obtained combining properly the results of the single partial tests.

In this case we want to test the hypothesis that the correlation between the index of policy effort and the index of performance is significantly positive. There are confounding factors present like the trend of the policy index (TREND), the existence of a SEZ (SEZ), the proximity to the coast (COAST) and the proximity to the Pearl River Delta (PRD), so we suggest, that for each of these four factors, the problem should be decomposed into many sub-problems, and apply the following procedure:

i) test of hypothesis on correlation for each single prefecture through the permutation methodology;

ii) combination of the partial p-values of the tests at step (i) obtaining a new p-value for each group (stratum) of prefecture;

iii) combining the p-values of the strata to obtain just one final global p-value.

For the combination of the partial p-values, at each level of the procedure, a suitable function, satisfying some weak and easyto-check properties is needed.

Formally, for a given prefecture $v$ in the stratum $s$, we test the null hypothesis $H_{0, v s}: \rho\left(I P I_{v s}, P E R F_{v s}\right) \leq 0$ against the alternative $H_{1, v s}: \rho\left(I P I_{v s}, P E R F_{v s}\right)>0$ where $\rho\left(I P I_{v s}, P E R F_{v s}\right)$ represent the Pearson's correlation between the index of performance and the index of policy effort for variable $v$. Let us indicate with $\alpha$ the significance level of the test and with $p_{v s}$ the p-value of this partial test: if $p_{v s}<\alpha$ then the null hypothesis is rejected and the correlation can be considered significantly positive. The application of a combining function $\psi(\cdot)$ on the p-values of stratum $s$, allows to obtain a partial p-value to test the following hypotheses related to stratum $s: H_{0, s}: \rho\left(I P I_{s}, P E R F_{s}\right) \leq 0$ against the alternative $H_{1, s}: \rho\left(I P I_{s}, P E R F_{s}\right)>0$. Using the Tippett combining function the partial p-value $p_{s}$ for each stratum $s$ is calculated from the test statistic $T_{s}=\psi\left(p_{v s} ; v \in s\right)=\max _{v \in s}\left(p_{v s}\right)$. Finally and similarly it is possible to apply a further combination of the p-values related to the strata for the global test $H_{0}: \rho(I P I, P E R F) \leq 0$ against the alternative $H_{1}: \rho(I P I, P E R F)>0$, and the global p-value for this test, for example applying the Tippett combining function, is obtained from the test statistic $T=\max _{s}\left(p_{s}\right)$.

The application and the interpretation of this methodology are simple but effective. The main advantages of it are:

i) it is distribution free, so no assumption about the distribution of the test statistic of the partial and global tests is needed and it can be applied even in presence of only eight observations, when asymptotic theory cannot be applied;

ii) it does not need to explicitly describe the dependence structure of the partial tests (i.e. to know the covariances between the partial test statistics or other information about the multivariate distribution of the tests) because it is implicitly taken into account through the permutation of the rows of the dataset and the use of the Tippett combining function. 
For these reasons we consider this method the most appropriate to test complex hypotheses in observational studies like the one we are dealing with.

\section{References}

Arvanitis, R., \& Jastrabsky, E. (2006, February). A regional innovation system in gestation: Guangdong. China Perspectives, 63, 14-28.

Arvanitis, R., Miège, P., \& Zhao, W. (2003). A fresh look at the development of a market economy in China. China Perspectives, 48, 50-62.

Arvanitis, R., \& Qiu, H. (2009). Research for policy development: Industrial clusters in South China. In M. Graham \& J. Woo (Eds.), Fuelling economic growth. The role of public-private research in development (pp. 39-85). Ottawa: CRDI/IDRC.

Barbieri, E., Di Tommaso, M., \& Huang, M. (2010). Industrial development policy and innovation in Southern China. European Planning Studies, $18(1)$, 83-105.

Barbieri, E., Di Tommaso, M. R., \& Rubini, L. (2009). Industria contemporanea nella Cina meridionale: Governi, imprese e territori. Roma: Carocci editore.

Barbieri, E., Di Tommaso, M. R., \& Rubini, L. (2009). Industrial development policies in Southern China: the Specialised Towns Programme. Economia e Politica Industriale, 3/2009 (pp. 179-198).

Bellandi, M., \& Di Tommaso, M. R. (2005). The case of specialized towns in Guangdong, China. European Planning Studies, 13(5), 707-729.

Cao, H. L., \& Chen, W. (2010). On the scientific research performance in high-tech industries in Guangdong Province. Industrial Engineering Journal, (1).

Chen, X. M., \& Cheng, P. Y. (2005). The formation development and upgrading of the clusters in Guangdong. Shangdong Economic Studies, 1, 68-71 (in Chinese).

Clark, J., \& Guy, K. (1997). Innovation and competitiveness. Brighton: Technopolis.

Demurger, S., Sachs, J. D., Woo, W. T., Bao, S., \& Chang, G. (2002). The relative contributions of location and preferential policies in China's regional development: Being in the right place and having the right incentives. China Economic Review, 13(4), 444-465.

Di Tommaso, M. R., \& Huang, M. (2010). Knowledge management, university-firm relations and industrial development in Southern China: the scenario and a case study on traditional Chinese pharmaceuticals. International Journal of Healthcare Technology and Management, 11(4), $283-295$.

Di Tommaso, M. R., \& Rubini, L. (2006). Cluster industriali e Specialized Towns nel Guangdong: la centralità del Delta del Fiume delle Perle. In M. R. Di Tommaso \& M. Bellandi (Eds.), Il Fiume delle Perle: La dimensione locale dello sviluppo industriale cinese e il confronto con l'Italia. Torino: Rosenberg\&Sellier.

DSTGG (Department of Science and Technology of Guangdong Government) (2003). The innovation of industrial clusters in Guangdong province. Publication of the Guangdong Provincial Department of Science and Technology (in Chinese).

DSTGG (Department of Science and Technology of Guangdong Government) (2006). Guangdong province government's suggestion on the promotion of the development of Specialized Towns (in Chinese), Official website of DSTGG. Available at http://www.zhyz.gov.cn/ accessed 15 November 2006.

DSTGG (Department of Science and Technology of Guangdong Government) (2006). Report on the summary of the five-year implementation of the Plan of ST technology innovation pilot test and an overview of the development of the STs. DSTGG Magazine on Specialized Towns Technology Innovation Dynamics, 15(6), $1-6$ (in Chinese).

DSTGG (Department of Science and Technology of Guangdong Government) (2008). Policy and instruments on specialized town technology innovation in Guangdong. Department of Science and Technology of Guangdong Province available at: http://www.zhyz.gov.cn/ (in Chinese).

DSTGG (Department of Science and Technology of Guangdong Government) (2008). Name of the specialized towns of Guangdong. Department of Science and Technology of Guangdong Province available at: http://www.zhyz.gov.cn (in Chinese).

DSTGG (Department of Science and Technology of Guangdong Government) (2008). Patterns of technology innovation platform in specialized town. Department of Science and Technology of Guangdong Province available at: http://www.zhyz.gov.cn/ (in Chinese).

Enright, M. J., Scott, E. E., \& Chang, K. -M. (2005). Regional powerhouse: the greater PRD and the rise of China. Asia: John Wiley \& Sons.

Fan, C. C. (1995). Of belts and ladders: State policy and uneven regional development in post-Mao China. Annals of the Association of American Geographers, 85(3), $421-449$.

Ge, W. (1999). Special economic zones and the opening of the Chinese economy: Some lessons for economic liberalization. World Development, 27(7), 1267-1286. GETDD (Guangzhou Economic and Technological Development District) (2003). Meeting the needs of both investors and businesses, informative brochure, GETDD.

Greater Pearl River Delta Business Council (2006). Report on Guangdong industrial restructuring: Opportunities and challenges for Hong Kong. Report available online at: www.cab.gov.hk

Greater Pearl River Delta Business Council (2006). The development of Western Pearl River Delta Region and its prospects for collaborations with Hong Kong. Report available online at: www.cab.gov.hk

Huang, X., \& Hu, C. W. (2007). Industry gathering style from the angle of origin and its characteristics: Take Guangdong province specialized town as example. Special Zone Economy, 5, 39 (in Chinese).

Huang, Y., Yang, Z. B., \& Meng, F. C. (2006). The empirical research and policy suggestion of the development of industrial clusters in Guangdong Province. Science and Technology Management Research, 12, 15-17 (in Chinese).

Inaba, J., Koolhaas, R., Leong, S. T., \& Chung, C. J. (2001). Pearl River Delta: Great leap forward, growth of modern China urban landscape. Harvard Design School.

Jin, H. (2007). Aspects of Guangdong Province. Guangzhou: Cartographic Publishing House of Guangdong Province.

Krug, B. (Ed.). (2004). China's rational entrepreneurs. London: Routledge Curzon.

Li, X. C. (2002). The acquisition and creation of capabilities and resources in the growth process of Clusters in Guangdong.Academic Research, 7, 10-12 (in Chinese).

Li, Y. P. (2006). The pattern and experience of the development of SME clusters in Guangdong. Enterprise Research, 311(7), 58-61 (in Chinese).

Lu, P. (2006). Specialized town is the strong engine to drive the economy of Guangdong: the five-year development of specialized town Technology innovation Pilot test. Journal of Guangdong Science and Technology, 8, 1-4 (in Chinese).

Maskel, P., \& Malmberg, A. (1999). The competitiveness of firms and regions. European Urban and Regional Studies, 6(1), 9-25.

National Development and Reform Commission (2009, January). The Outline of the Plan for the Reform and Development of the Pearl River Delta (2008-2020). Policy Release (pp. 1-122).

NBS (National Bureau of Statistics of China) (2009). Guangdong statistical yearbook. Beijing: China Statistics Press.

NBS (National Bureau of Statistics of China) (various years), Guangdong Statistical Yearbook, Beijing, China Statistics Press.

Nee, V., \& Cao, Y. (1999). Path dependent societal tranformation: Stratification in hybrid mixed economies. Theory and Society, 28(6), 799-834.

Nee, V., \& Opper, S. (2007). On politicized Capitalism. In V. Nee \& R. Swedberg (Eds.), On capitalism (pp. 93-120). Stanford University Press.

Parish, W. L., \& Michelson, E. (1996). Politics and markets: Dual transformations. The American Journal of Sociology, 101(4), 1042-1059.

Peng, W., \& Chen, Z. (2009). On the countermeasures of institution contruction of regional innovation system of Guangdong Province. Science and Technology Progress \& Policy, (18) (in Chinese).

Pesarin, F., \& Salmaso, L. (2010). Permutation test for complex data. John Wiley and Sons Ltd.

Qiu, H., \& Xu, J. (2007). The actions of local governments in technological innovation in industrial clusters. In H. Qiu (Ed.), Regional innovation and development of entreprises (pp. 3-24). Beijing: Economic Science Publishing House (jingji kexue chubanshe) (in Chinese).

Simmie, J. (2004). Innovation and clustering in the globalised international economy. Urban Studies, 41, 1095-1112.

Siu-Wai, W., \& Bo-Sin, T. (2005, August). Challenges to the sustainability of 'development zones': a case study of Guangzhou Development District, China. Cities, 22 (4), 303-316

Tang, Q. Y., Xie, H. M., \& Lan, H. L. (2005). Guangdong industry gathering's present situation, development trend and countermeasure: Research based on Geordie coefficient. Special Zone Economy, 11, 22-24 (in Chinese).

Unger, J., \& Chan, A. (1999, July). Inheritors of the boom: private entreprise and the role of local governement in a rural South China township. The China Journal, 42 , $45-74$.

Wang, J. (2002). Innovation process of enterprise cluster. Management World, 10, 102-110 (in Chinese). 
Wang, J. (2004). Developing innovation-based industrial clusters: Policy recommendation. Economic Geography, 7, 433-436 (in Chinese).

Xie, M. Q. (2003). Disseminating the experience of Specialized Town technology innovation and accelerating the development of town economy (in Chinese). Report presented at the working conference on Guangdong specialized town technology innovation, Department of Science and Technology of Guangdong Province, October.

Xie, M. Q. (2006). Accelerating the development of ST, and improving GD industrial competitiveness. Director XieMingquan's speech on the conference of GD promotion of ST. Guangdong KeJiJournal of Guangdong Science and Technology, 9, 1-3 (in Chinese).

Zhang, X. G. (1999). Foreign investment policy, contribution and performance. In Y. R. Wu (Ed.), Foreign direct investment and economic growth in China. Cheltenham: Edward Elgar.

Zhang, M., \& Ling, H. (2003). Building Specialized Town technology innovation platform with rich content: an interview to Mr. Ma Xianmin, Vice Director of Department of Science and Technology of Guangdong. Journal of Guangdong Science and Technology, 2, 15-18 (in Chinese).

Zhao, X. X. (2007). Empirical research of the development stage of Guangdong enterprise clusters. Journal of Tianjin Manager College, 9(1), 33-34 (in Chinese). Zhu, X. D. (2005). Guangdong specialized leading towns. Guangzhou: Yangcheng Evening News Press (in Chinese).

Elisa Barbieri is Researcher in Applied Economics at the Department of Economic Studies of the University of Ferrara, Italy. She teaches Applied Economics at the Faculty of Natural Sciences, Physics and Mathematics, University of Ferrara. She has held visiting appointments at the University of California Los Angeles (UCLA) and at South China University of Technology (SCUT). Her research interests include industrial economics and policy, policy evaluation and international industry analysis.

Marco Di Tommaso is Professor of Applied Economics at the Department of Economic Studies of the University of Ferrara, Italy. He is Honorary Professor at the South China University of Technology, coordinator of the "China and Italy Research and Learning Project" and Director of the "China and Italy School of Policy". He has published several books and articles on the topics of industrial development and industrial development policies in China, small businesses and industrial clusters, health industry and high tech development, United Nations and industrial development.

Stefano Bonnini is Researcher in the Department of Mathematics, University of Ferrara (Italy) and he is member of the Italian Statistical Society. He is Professor of Statistics at the Faculty of Economic Studies of University of Ferrara (Italy). His main research interests include non parametric statistics, permutation statistical tests and performance analysis. On these topics he has published four books and many articles in international journals and took part to various international conferences as a speaker. 